\title{
Tuberculosis Patients' Perspective of Quality of Care Provided By Nurses after Implementing Nursing Intervention at Chest GovernorateHospitals in Gharbia
}

\author{
${ }^{1}$ Rabea Abd Rabo Mohamed Abd Rabo, ${ }^{2}$ Amaal Mohamed Ahmed El-zeftawy, \\ ${ }^{3}$ Rada AbdEl-Fatah Abo-Gad, \\ Lecturer of Community Health Nursing Faculty of Nursing, Tanta University. \\ Assistant Professor of Administration Nursing Faculty of Nursing, Tanta University.
}

\begin{abstract}
Tuberculosis (TB) is a significant global infectious disease, infecting 9.4 million patients in 2009 and nearly 14 million people living with the disease worldwide.

The Aim of this study: Assess tuberculosis patients' perspective of quality of care provided by nurses after implementing nursing intervention at chest hospitals in Gharbia Governorate and evaluates the effect of educational intervention on nurse's knowledge and attitude regarding tuberculosis disease.

Material and Methods: This study was conducted in Tanta and El Mahalla chest hospitals in Gharbia Governorate. The study sample included all old and newly diagnosed cases (at least two weeks on treatment) with $T B$, and 149 nurses form both chest hospitals. Data were collected through an interview sheet which includes socio-demographic characteristics, personal history of chronic diseases, patients' knowledge about TB and A questionnaire sheet include socio-demographic characteristics related to the nurses, the nurses' knowledge about tuberculosis and their attitude.

Results: The majority of the interviewed patients were male (89.2\%) and most of them (70.3\%) were smoking patients. The attitude of the patients' regarding to performance of the TB facility was (59.8\%), while the total mean percent for patient attitude about the importance of the TB quality aspects was (100\%). The majority of the studied nurses were Bachelor; the total score of nurses' knowledge was highly significant in pre and post intervention of educational program.
\end{abstract}

Conclusion and Recommendations: There is a need for in-service training for staff to provide patients with effective counseling.

Keywords: Tuberculosis, quality of care, performance of the TB facility, importance of the TB quality aspects.

\section{Introduction}

Tuberculosis (TB) is one of the greatest public health problems in the world. Tuberculosis (TB) is one of the most important causes of mortality and morbidity in developing countries and is responsible for about $25 \%$ of all preventable deaths ${ }^{(1,2)}$. Tuberculosis (TB) is a significant global infectious disease, infecting 9.4 million patients in 2009 and nearly 14 million people living with the disease worldwide ${ }^{(1)}$.

Tuberculosis is a medico-social problem: factors such as socio-economic and nutritional status, perception of the disease, health-seeking behavior and access to health care, influence its frequency and prognosis. The main reasons for the increase of the global burden of TB are the inadequate health services, improper management practices resulting in poor case detection, misdiagnosis, and maltreatment. Demographic changes in world population (increasing changing age structure), and the impact of increasing HIV add to TB burden. Treatment of TB is considered a cost-effective health intervention in developing countries; prompt diagnosis and successful treatment shorten the chain of transmission. Development of serious complications such as: extreme poverty, the HIV epidemic, and the emergence of drug resistance have made TB control incredibly difficult in many settings. So the World Health Organization (WHO) Stop TB Strategy set targets to half the world prevalence and reverse the incidence of TB by 2015 and to eliminate TB as a public health threat $2050^{(3-5)}$.

Physicians, nurses, medical students and other health care workers are at high risk for nosocomial M. tuberculosis infection in health care settings ${ }^{(6)}$. Tuberculosis is a global health problem and the World Health Organization (WHO) in 2010 reported that someone in the world is newly infected with TB bacilli every second. One-third of the world's population is currently infected with the TB bacillus. Also, 5-10\% of people who are infected with TB bacilli (but who are not infected with HIV) become sick or infectious at some time during their life ${ }^{(7,8)}$. Tuberculosis (TB) is among the top ten causes of death in the world. TB is an important public health problem in the Eastern Mediterranean Region of the World Health Organization. Every year, the disease kills 136,000 people and affects 630,000 in that region ${ }^{(1)}$. Tuberculosis is a major contributor to the 
Tuberculosis patients' perspective of quality of care provided by nurses after implementing ...

disease burden in developing countries. It is considered the third most important public health problem in the Egypt. The global plan to stop tuberculosis recommended the sustainability and accessibility of the standardized short-course chemotherapy for all cases of tuberculosis. The directly observed treatment strategy (DOTS) is required to ensure treatment adherence and it helps to reinforce patients' motivation to continue treatment ${ }^{(9-12)}$

In terms of incidence of tuberculosis, Egypt is ranked among the mid-level incidence countries. Tuberculosis in Egypt is considered an important public health problem. Tuberculosis control consists of a variety of activities carried out by different persons in governmental, non-governmental and private organizations and institutions. These activities include immunization (BCG); case finding and treatment; health education; and, surveillance of the disease in the community. The Ministry of Health and Population (MOHP) has established the National Tuberculosis Control Program (NTP) in 1979. It is a detailed plan of action for effective TB control. NTP is implemented through the Directorate-General of Chest Diseases and carried out through: 111 Chest Disease Dispensaries and 39 Chest Disease Hospitals. Tuberculosis control activities are currently integrated through the primary health care system which is constituted of more than 4000 Primary Health Care Centers $(\mathrm{PHCs})^{(13)}$.

Disease-related stigmas negatively influence treatment, including that of TB. TB stigmatization is interesting in that the initial social shunning was largely eliminated with a TB cure, but stigmas re-emerged when it became a marker for HIV/AIDS. The effect was amplified when the cost effective combination of TB and HIV/AIDS treatment was chosen as a recommended strategy .Disease-related stigmas also negatively affect public attitudes especially nurses, medical staff and health workers toward prevention, service provision, and health-related policies ${ }^{(14)}$. Nurses play a crucial role in tuberculosis control program. The International Council of Nursing (ICN) believes that nurses are in a position to advocate for strong tuberculosis control programs and to implement the elements of DOTS. Nowadays most tuberculosis treatment is carried out in the community settings. Treatment is best supervised by nurses in regular contact with the patient. The main principle of nursing intervention is the integrated organization of multiple activities to achieve specific outcomes for patients (12).

Health education continues to be one of the most important strategies in the fight against TB. Efforts are directed at nurses, all health care workers and patients to make them more informed and aware of all aspects of TB disease, its treatment and the basic rules to prevent the spread of infection to others in the community. Health education plays a key role in encouraging patients to seek diagnosis for TB and to adhere to the treatment regimen ${ }^{(15)}$. Nurses make up by far the largest group of health care workers in any part of the world and as in most areas of health care they often undertake the bulk of the work in TB control ${ }^{(16)}$. So health education play an important role in change nurses knowledge and attitude regarding tuberculosis.

The main objective of direct health care units is to provide services with the best quality possible, involving desirable characteristics such as effectiveness, efficiency, equity, acceptability, accessibility and suitability. Several measures are used to evaluate services directly provided to the population and user satisfaction is one these measures. Some transmissible diseases such as tuberculosis (TB) are persistent, present high rates of incidence and are considered a public health problem with deep roots that reflect an inefficient structure of the health services and also the population's poor living conditions. One of the problems related to $\mathrm{TB}$ is the high rate of treatment abandonment. Users satisfied with services tend to adhere to their prescribed therapy and treatment adherence is essential in the case of TB, since one of the main problems presented by the National TB Control Program refers to the non-adherence of TB patients to their treatment. Non-adherence leads to a reduced number of cases whose outcome is a cure and to an increased number of cases that develop resistance to the medication used in TB treatment. Such a context poses a great challenge to health professionals and managers who are required to search for strategies to overcome such difficulties, such as increasing treatment adherence through the user increased level of satisfaction. User satisfaction in relation to TB control was assessed in this study in relation to performance and important of services for the patients ${ }^{(17-19)}$.

\section{Aim Of The Study}

\section{The Aim Of This Study Was To}

1. Assess tuberculosis patients' perspective of quality of care provided by nurses after implementing nursing intervention at chest hospitals in Gharbia Governorate.

2. Evaluate the effect of educational intervention on nurse's knowledge and attitude regarding tuberculosis disease.

\section{Research Hypothesis}

There is significant improvement of the quality of care provided by nurses for TB patients as well as improvement performance of TB facility. 


\section{Study Design}

\section{Materials And Methods}

This was a descriptive study of knowledge, practices and quality of care provided for pulmonary tuberculosis (TB) patients; a quasi- experimental study was conducted to evaluate the effect of health education intervention on the nurses' knowledge and attitudes regarding tuberculosis disease and tuberculosis patients.

\section{Setting Of The Study} Sample

This study was conducted in Tanta and El-Mahalla chest hospitals in Gharbia Governorate.

The study sample included all old and newly diagnosed cases (at least two weeks on treatment) with pulmonary TB, both sex and admitted to the previous settings through three months started from April and ended at July 2012. Also the study sample included all nurses have chance of direct contact with TB patients in previous settings. The total number of the study sample through this period was (37) patients and (149) nurses form both chest hospital.

\section{Tools Of The Study}

Two tools were used by the researchers in order to obtain the necessary data.

\section{Tool ( I ) An Interview Sheet To TB Patients}

This tool was used for TB patients and it included the following parts

Part (a) Socio-demographic characteristics related to the patients diagnosed with TB: - It included the following data

1- Personal Data: -age, sex, education, occupation, place of residence (rural-urban), marital status, number of family members and family income.

2- Housing condition: number of rooms, state of ventilation, water supply, and presence of domestic animals.

Part (B): Personal History Of Chronic Diseases Such as Chest diseases and Diabetes Mellitus (DM).

\section{Part (C): Knowledge Of Patients About TB}

It included the following topics: - Meaning of TB, modes of transmission; severity of disease; its curability; consequences of interrupted treatment and sources of information.

\section{Part (D): Measuring The Quality Of TB Services: The Patient's Perspective}

This was conducted by using QUOTE (Quality of Care as seen through the Eyes of the Patient). It is a standardized tool for patient interviews, which capture patient perspectives and which can be used by National TB Program staff to improve the quality of TB services and stay accountable to TB patients.

The QUOTE-TB questionnaire is being developed by the Regional Centre for Quality of Health Care (RCQHC) and National TB Programs (NTPs) of Uganda, Kenya, and Malawi, with technical support from Royal Tropical Institute (KIT), KNCV Tuberculosis Foundation and the Netherlands Institute for Health Services Research (NIVEL) ${ }^{(20)}$.

QUOTE-TB is a management tool which allows National TB Programs (NTPs) to measure the performance of TB services from the patient's perspective at the health facility and to focus quality improvement interventions at the various levels of health care. It could be used by NTP supervisory staff as part of supervision activities, with the assistance of health staff trained to take interviews.

\section{QUOTE-TB Consists Of The Following Parts}

A) A questionnaire to assess the performance of TB services as experienced by patients. The performance questionnaire is included the following items:-

1. Availability of TB services (9 items)

2. Information (7 items)

3. Patient- provider interaction and counseling (8 items)

4. Infrastructure (4 items)

5. Procedures and tests ( 7 items)

6. Costs and payment (3 items)

7. Support (2 items)

b) A questionnaire to identify which quality issues are important to patients. This importance questionnaire is included the following items:-

1. Availability of TB services (9 items) 
2. Information (7 items)

3. Patient- provider interaction and counseling (8 items)

4. Infrastructure (4 items)

5. Procedures and tests ( 7 items)

6. Costs and payment ( 3 items)

7. Support (2 items)

The average time taken for a performance and importance interview was approximately 10 to 20 minutes per patient. The essence of QUOTE-TB is to calculate the quality impact (QI) score, by multiplying the importance and the performance scores.

Tool (II ) A Questionnaire Sheet For Assessing Nurses' Knowledge And Attitude Regarding TB And TB Patients

This tool was developed by the researchers; it included the following parts:

Part ( 1) Socio-Demographic Characteristics Related To The Nurses. This included: name or code number of each nurse, age, marital status, residence, qualifications and years of experiences.

Part (2 ) The Nurses Knowledge About Tuberculosis

It covered the following items.

- Knowledge Related To Meaning, Causes And Mode Of Transmission: Meaning of TB, common age group affected by TB, its causes, routes of TB transmission, organs affected by TB, high infection source for TB, mode TB transmission and the reduction of the indoor transmission of TB.

- Knowledge Related To Symptoms And Signs And Diagnosis Of TB: Symptoms and signs of pulmonary $\mathrm{TB}$, specimen used to diagnose pulmonary $\mathrm{TB}$, ideal time of its collection, diagnostic tests of pulmonary $\mathrm{TB}$, curability of TB and factors favoring TB.

- Knowledge Related To Prevention And Treatment Of TB: Measures of prevention of TB, the modality of treatment for TB, phases of treatment, commonly drugs used of treatment for TB, duration of courses of treatment for TB, the vaccine used to minimize TB infection and age of administration, the dose of PPD administered in Mantoux test, duration of reading of Mantoux test, safe method of disposing sputum of infected person and vitamin used to prevent the side effect of tablet INH.

\section{Part (3 ) Attitude And Stigma Of Nurses Toward Tuberculosis Patients}

This was measured by using a scale. The scale was originally developed by Dixit etal.,(2006) and Somma et.al., ( 2008) ${ }^{(21,22)}$ and modified by the researchers to suit the study culture. The scale consisted of a twenty seven statements measuring nurses' attitudes toward tuberculosis, patients with tuberculosis and their attitude toward herself if she became.

The nurses were asked to select the answer on each of a twenty seven items according to how accurately the item described their attitudes and stigma toward tuberculosis, patients with tuberculosis and their attitude toward herself if she became. Each question consisted of five responses (strongly disagree, disagree, neutral, agree and strongly agree) where 'strongly agree' and 'agree' indicated presence of attitude and perceived stigma and 'disagree' and 'strongly disagree' indicated absence of attitude and perceived stigma. An answer consistent with attitude and stigma towards TB and patients with tuberculosis was scored with one point. An answer not consistent with attitude and stigma towards TB was scored as zero point.

There were four negative statements and twenty- three positive statements. The nurses were asked to select the answer on each of a twenty seven items according to how accurately the item described their attitudes and feelings toward TB disease, patients with tuberculosis .and their attitude toward herself if she became. A total attitude and stigma score for TB disease, patients with tuberculosis and their attitude toward herself if she became was created by summing the scores of all questions. The attitude and stigma score ranged from 1 to 5 , with the higher the score, the greater the degree of attitude and stigma towards TB. Nurses who had an attitude and stigma score of equal to or greater than the mean score of the study sample were categorized as having high stigma towards TB disease, patients with tuberculosis and their attitude toward herself if she became. On the other hand, nurses who scored an attitude and stigma score below the mean were categorized as having low attitude and stigma towards TB disease, patients with tuberculosis and their attitude toward herself if she became. Since the attitude and stigma scores were normally distributed, the mean was used to classify the study sample as having high or low stigma. 


\section{1- Official Permission}

\section{Methods}

To conduct the study was obtained by the researcher from responsible authorities (Dean of the Faculty of Nursing Tanta University to Directorate of Health Affairs in Gharbia Governorate; responsible authorities of Ministry of Health and Population and finally the principals of chest hospitals in Tanta and El-Mahalla) as well as all participants from patients and nurses.

\section{2- Ethical Considerations}

a- nurses and patients' informed consent was obtained.

b- Confidentiality of information, anonymity and the right to obtain or terminate participation at any time will be respected.

d- All participants (nurses and patients) were notified about time, methods and anticipated benefits from this study.

\section{3- The Developed Tools}

were introduced to jury committee before conducting the study to test their validity. This jury committee was consisted of five experts two of them from public health and preventive medicine and the rest of them form department of community health nursing. Delete from QUOTE-TB tool the part responsible about TB relationship to HIV based on the opinions of jury committee.

\section{4- Data Collection}

- Tool I administered for each patient one time only.

- Tool II administered individually to each nurse of the study sample before start program.

- Tool II part (2 and 3) administered also immediate post program.

\section{5- Implementation Phase Of The Program}

The first step of developing educational intervention program was formulating program objectives. The general aim of the program was to evaluate effect of health education intervention on the nurses' knowledge about and attitudes regarding tuberculosis disease and tuberculosis patients. The field work of this study was done in three months starting from the (April 2012 to the July 2012). Each nurse was first informed about the program objectives to attain their active participation and cooperation during the implementation of the program.

\section{The Researchers Visited Each Hospital Several Times}

- First time to meet the director of each hospital, introduce the official letter, explain the objectives of the program and determine the time of the next visit to start the program implementation.

- Second time for explanation of the purpose of the study and before performing of the program the researchers were done meeting with chief nurses of all departments and explained the purpose of the study for them to gain their cooperation and ask the chief nurse of each department to select the suitable time for their staff because the nurses are very busy during the morning shift ( so the researchers take one or two nurse form each department so the number of nurses through each session ranged from 7 to 10 nurses).

- Then the researchers visited each hospital two days each week through the three months of the study period. The contents of the program was organized and presented in one session for each group of nurses. This session was $(60$ minutes). This was imparted to the nurses through lecture, group discussion with the help of audio-visual aids (power point presentation). This session was followed by question-answer session to clarify their doubts and answer their questions related to tuberculosis (45 minutes).The session was done in nurses room and / or doctor's room at each hospital. Then the questionnaire was again administered to the nurses (immediate post-test).

- At the end of each day of the study period the researchers met the TB patient admitted to the chest hospital at least two week ago. At the first the researchers explain the purpose of the study to each patient to gain his cooperation and had his oral consent to participate in this study. The researchers met each patient alone. The average time taken for interview was approximately 20 to 30 minutes per patient.

- Through the study period three patient refused cooperation with the researchers.

\section{6- Evaluation Of The Program}

Two assessments were done to the nurses in order to test their knowledge about and attitude regarding TB and TB's patients. Therefore, tool (II) parts (2and 3) were used two times before and immediate implementation of the program. 
Tuberculosis patients' perspective of quality of care provided by nurses after implementing ...

\section{7- Statistical Analysis}

Results were tabulated and statistical analysis was performed with Statistical Package for Social Science (SPSS version 13). For qualitative data, comparison between two groups was done using Chi-square testing $\left(\mathrm{X}^{2}\right)$. P values of $<0.05$ were considered statistically significant. The results were expressed as mean \pm SD.

\section{Results}

Quality of nursing care provided to TB patient regarding to importance of TB quality aspects and performance of facility according to patient response were very important in all dimensions of patients' care. The nursing intervention in the present study improved significantly the total mean score of nurses' knowledge related to all tuberculosis (TB) items, and there is a minimum change in the attitude of nurses' pre than post program.

The patients demographic characteristics are shown in Table (1): Nearly two third (64.9\%) of respondents fell in age group 40 and more years old, and all patients`age ranged from 15-82 years old with mean score $41.216 \pm 15.094$. Males constituted the majority $(89.2 \%)$ of the interviewed patients, $70.3 \%$ were married and $32.4 \%$ had from 2-3 children. As regard to residence, more than half (59.5\%) were rural residents and $43.2 \%$ were illiterate. About two third (62.2\%) were working. Majority of the studied patients (70.3\%) were smoking patients. $51.4 \%$ of TB patients were not known about TB before they have it and the majority $(70.3 \%)$ haven't any difficulties to reach to TB hospital.

Table (2): Reveals patients' general knowledge about TB. As it obvious from the table, the total mean percent of the patients was $48.2 \%$ with mean scores $26.4865 \pm 10.8976$. The highest mean percent $(89.2 \%)$ was for searching of the patient for concealing before they were reached to the TB hospital, with mean scores $0.8918 \pm 0.3148$. On the other hand; the lowest mean percent $(13.5 \%)$ was for patient knowledge about curability of the disease, with mean scores $0.4054 \pm 0.4977$.

Figure (1): there is no statistical significant difference between patient knowledge regarding TB and their level of education. The highest percent $(56.3 \%, 75 \%, 55.6 \%$ and $50 \%)$ of the studied patients had fair level of knowledge, respectively.

Table (3): shows quality of nursing care provided to TB patient regarding to importance of TB quality aspects and performance of facility according to patient response. The table presents that all studied patients $(100 \%)$ were reported that infrastructure of the TB facility they are visiting and, costs and payment were very important aspects of quality, also (97.3\% and 94.6\%) of the studied patients perceived information about TB and its treatment, TB procedures and tests and, patient - provider interaction and counseling dimensions very important aspects of quality, while non of them perceived all items not important. As regard performance of the facility in the quality aspects, all patients (100\%) reported that the facility, never perform support received from the TB facility as well as they usually do costs and payment. Majority (89.2\%) of studied patients reported that TB procedures and tests sometimes done while, $51.4 \%, 48.6 \%$, and $37.8 \%$ of them perceived that the facility had availability of services, patient - provider interaction and counseling and, information about TB and its treatment dimensions, respectively.

Table (4): shows distribution of nurses according to their demographic characteristics. $48.3 \%$ of nurses fell in age group 20-30 years old, and all nurses age ranged from 21-58 years old, with mean score $30.87919 \pm 7.778967$. About one third (31.6\%) of nurses had 10-20 years of experience, with mean score $9.677852 \pm 8.362778$. Nurses who are married constituted the majority $(93.3 \%)$ of the studied sample. As regard to residence, fifty percent $(50.3 \%$ ) of nurses were rural residents and $59.1 \%$ of them had bachelor degree.

Table (5): presents distribution of nurses according to their mean score of knowledge regarding TB in the ElGharbia Governorate pre and post the educational program. As evidence that, there was an increase in nurses total percent mean of knowledge from $72.2 \%$ pre-program up to $89.2 \%$ post program. Nurses' total mean knowledge and all its items on tuberculosis were improved significantly at $\mathrm{P} \leq 0.05$ from preprogram. Preprogram prevention measures and treatment of TB was the lowest (62.9\%) nurses' knowledge mean percent, with mean scores $20.778+3.8341$. While, the highest mean percent was $76.9 \%$ for signs, symptoms and diagnosis of TB with mean scores $19.221+3.7123$. Post program, the highest $(93.8 \%)$ nurses knowledge mean percent was for the definition, causes and mood of transmission of TB with mean score $20.95 \pm 2.06$, while, the lowest mean percent was $86.1 \%$ for nurses knowledge regarding preventive measures and treatment of TB, with mean scores $28.402+2.8018$. 
Tuberculosis patients' perspective of quality of care provided by nurses after implementing ...

Table (6): reveals distribution of nurses' level of knowledge about tuberculosis in the Al-Gharbia Governorate pre and post the program. Preprogram, out of the total number of respondents149 only 75 (50.3\%) of nurses had good level of total knowledge, and was improved to be $144(96.6 \%)$ post program, with significant improvement on total level of nurses' knowledge and its subscales at $\mathrm{P} \leq 0.05$ from preprogram. Out of the total number of respondents only $77(51.7 \%)$ of nurses had good level of knowledge regarding to definition, causes and mood of transmission at preprogram, and was increased to 139 (92.3\%) nurses post program. 27 (18.1\%) of the studied nurses were at poor level of knowledge at preprogram, but this number was decreased to only 2 (1.3\%) nurses at post program. Finally, more than half $(57.7 \%)$ of nurses were at good level of knowledge regarding to preventive measures and treatment of $\mathrm{TB}$, and this percent was improved to $85.2 \%$ at pot program.

Table (7): reveals Attitude of nurses regarding TB disease, TB patients and their attitude toward herself if she became TB patient in the Al-Gharbia Governorate pre and post of the program. The table showed that there is a minimum change in the attitude of nurses pre than post program as observed by, preprogram $37.6 \%$ of total studied nurses were in low attitude and this percent was decreased to $36.2 \%$ post program. Out of all nurses, 95(63.7\%) were in high level of attitude regarding to TB disease and TB patient at preprogram and this percent was slightly increase $(66.4 \%)$ post program. On the other hand, only $47(31.5 \%)$ of studied nurses were in high level of attitude toward herself if she became TB patient at preprogram and this percent was improved to $38.3 \%$ post program. There were no statistical significant differences at $\mathrm{P} \leq 0.05$ in relation to all items.

\section{Discussion}

Tuberculosis is still a major threat to the global health. The demand for quality care at a reasonable cost has created pressure to demonstrate positive relationships between practice and outcomes (23). Little is known

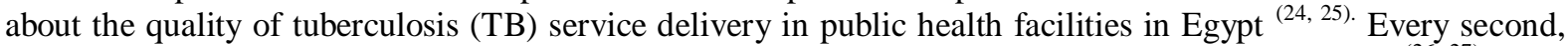

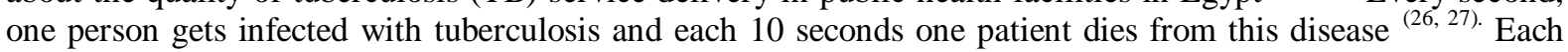
patient can infect 10 to 15 people (28). The World Health Organization (WHO) distributed it as an emergent disease in the world in 2000 and recommended to control this disease ${ }^{(29) .}$

This study assessed the quality of TB care based on the national guidelines for TB care in public health care facilities. Structural factors relating to organization and management in health facilities were used to assess the extent to which TB care is accessible and convenient to patients. The Aim of this study was to assess effect of educational intervention on nurse's knowledge and attitude regarding tuberculosis disease and quality of care provided by nurses to tuberculosis patients from the perspective view of the patients. In present study, the quality of TB care based on by using QUOTE (Quality of Care as seen through the Eyes of the Patient). It is a standardized tool for patient interviews, which capture patient perspectives and which can be used by National TB Program staff to improve the quality of TB services and stay accountable to TB patients.

Tuberculosis is affecting every one regardless of age but a majority of the respondents (64.9\%) were aged between 40 years and more, while (Mweemba, et.al., 2008) who found that the majority of the respondents (77.7\%) were aged between 20-39 years, as well as study done in (Ghana 2010) stated that the mean age of the respondents was 35 years $(30,31)$.

The present study revealed that more than two third of the subjects were married, and the majority of the studied sample $43.2 \%$ were illiterate and 59.5\% were from rural area. This in accordance with (Mesfin, et.al. 2009) reported that the 237 patients were interviewed; typically they were illiterate (61\%), married (56\%) and rural residents $(56 \%)^{(19)}$. The study done in (Ghana 2010) reported that the patients' education levels ranged from elementary to middle school level, but the majority of the studied sample had no formal education at all, so the majority of them cannot read and write ${ }^{(31)}$.

\section{Patient's General Knowledge About Tb}

It was maybe not surprising that; TB Patients showed a fair level of knowledge about, (general aspects of tuberculosis, sign and symptoms and types of investigation). This was in contrast the study done in Zambia by (Mulenga, et.al. 2010) that TB Patients respondents showed a good level of knowledge about, general aspects of tuberculosis, and sign \& symptoms) ${ }^{(32)}$. On the other hand; study done in Pakistan by (Ahmed, et.al. 2006) stated that poor knowledge of TB patients concerning their disease ${ }^{(33)}$. However, our study revealed vast difference in knowledge regarding searching of the patient for concealing before they were reached to the TB hospital. This was in contrast the study done in (Ethiopia 2010) showed that $46 \%$ of patients seeking care at health facilities did so after informal treatment failed ${ }^{(22)}$.

Moreover; the lowest mean percent was for time of taking medication followed by patient knowledge about curability of the disease. This was in contrast the study done in (Sudan 2007) The majority (80.3\%) of respondents in this study believed that TB is a curable disease This may be explained by the fact that most of the respondents were interviewed after having treatment for a period of time after which they felt free of symptoms. This improvement is a useful indicator that TB is a curable disease ${ }^{(34)}$. 
According to our conceptual framework, over all patients' knowledge of the disease is low, mainly due to poor health education given by nurses for their patients about tuberculosis. Consequently, it is important that patients counseling and good communication improve patient knowledge as well as their compliance to the disease. In contrast to completely (Moharana, et.al. 2009) observed that patient with higher literacy had a better concept on disease, importance of treatment adherence \& follow-up sputum examination ${ }^{(35)}$.

Studies conducted in (Bangladesh; 1999) have shown that well conducted community health education campaigns can affect the level of knowledge and produce favorable attitudes towards tuberculosis ${ }^{(36)}$. The highest percent of the studied patients had fair level of knowledge especially whom read and write; this was in accordance with (Hoa, et.al. 2003) stated that individuals who read and write were more likely to know about $\mathrm{TB}{ }^{(37)}$. While study done in (Vietnam 2009) stated that knowledge about basic facts related to TB was in general poor $^{(15)}$.

\section{Quality Of TB Care From The Perspective Of Patients}

The study revealed that the performance of TB facility (Availability of services, Information about TB and its treatment, Patient - provider interaction and counseling, Infrastructure of the TB facility you are visiting, TB procedures and tests, Costs and payment as well as Support received from the TB facility you are visiting.) were fair quality of TB services delivered in two hospitals represent $(59.8 \%)$; this is in contrary with the results of (Mesfin, et.al., 2009) who stated that, the poor quality of TB services and sub-optimal implementation of district control activities in public health facilities may be due to the provision of TB care by poorly trained and inadequately supervised. As regard daily TB services were available in (70.8\%) in the two hospitals, this is in agreement with the results of (Mesfin, et.al., 2009) who found that, daily outpatient TB services were available in $31(71 \%)$ of 44 health facilities ${ }^{(19)}$. On the other's hand the study done in France by (Salomon et.al 1999); stated that the quality of care scores were strongly related to departments, regardless of patient and hospitalization characteristics. These results tend to indicate that the measurement tool is more sensitive to departments' levels of performance. Regarding Infrastructure of the TB facility we are visiting, the highest percentage was usually done and all the patients say it is very important a more appropriate structure increase the probability of the care delivery being considered to have a higher quality ${ }^{(38)}$. In contrast, (Lafaiete, et.al., 2011) who stated that; it is important to review the aspects related to infrastructure in order to implement the necessary structural repairs to improve the environment, accommodations and waiting time, consequently improving the dynamic of consultations and supervised medication ${ }^{(17)}$.

The importance of TB quality aspect related to (Availability of services, Information about TB and its treatment, Patient - provider interaction and counseling, Infrastructure of the TB facility you are visiting, TB procedures and tests, costs and payment as well as support received from the TB facility you are visiting) were $100 \%$; this indicate that the quality of care provided to TB patient by this hospitals facility was not sufficient for the patients. As regards availability and access of health services is very important regard our patients; this is in accordance of (Lafaiete, et.al., 2011) who found that access of health services is valuated in the Brazilian context and most users reported being satisfied in relation to wait time ${ }^{(17)}$.

More than two third of the patients satisfied about provider interaction and counseling, this is in accordance of (Lafaiete, et.al. 2011) who stated that; most patients were also satisfied with guidance provided by health professionals. Attention to the quality in patient care is important in every setting ${ }^{\text {(17) }}$. Billingsely, et.al (2011) sated that the gap in what is done and what should be done can be closed by providers who implement the principles of quality improvement and have good tools and resources to do so ${ }^{\text {(39) }}$. As regarding support received from the TB facility you are visiting; the patients attending public hospitals experienced lower levels of satisfaction with technical quality of TB care, responsiveness to patient preferences, and patients' understanding of potential problems of TB medicines this is in agreement with Babikako, et.al (2011) ${ }^{(40)}$.

\section{Nurses' Knowledge About TB}

As regard nurses' knowledge about TB the present study revealed that more than half of the studied nurses have good mean score of knowledge about TB in pre educational program this may be attributed to the majority of the studied sample was bachelor degree, while the majority of the studied nurses have $96.6 \%$ score of knowledge in post of the educational program. There was a significantly difference between their mean scores before and after intervention of the educational program. This is in accordance with results of the study done in Iraq by Hashim, et.al (2003) who revealed that the majority of the studied sample had good knowledge about TB, and explain the high rate of good knowledge due to the majority of the studied sample had a diploma qualification, their age and duration of their work ${ }^{(41)}$.

In contrary, the study done in Egypt by (Ahmed, et.al 2011), who found that lack of knowledge among nurses regarding tuberculosis ${ }^{(12) .}$ In an area of South Africa with poor TB treatment outcomes, (Naidoo, et.al 2011), found that the overall knowledge of nurses, doctors and other healthcare workers who participated in a 28-day comprehensive training programme improved, but the change was not clinically significant. Of the 
Tuberculosis patients' perspective of quality of care provided by nurses after implementing ...

five participating categories of $\mathrm{HCWs}$, nurses recorded the lowest overall knowledge after the training, achieving their lowest results in the domains of TB patient management and TB program monitoring. Nevertheless knowledge about TB diagnosis and treatment in our surveyed population was fair ${ }^{(42)}$. While, an exploratory study was done in a district in Vietnam, found that knowledge about the spread of TB is limited ${ }^{(43)}$. In India; (Singla, et.al. 1998) stated that nurses still have inadequate knowledge regarding the tuberculosis ${ }^{(44)}$.

\section{Nurses' Attitude About TB}

According to the attitude of nurses regarding TB disease, TB patients and attitude toward her-self if she became TB patient in pre and post the program, the study showed that there is a minimum change in the attitude of nurses' pre than post program as observed by (63.7\%) were in high level of attitude regarding to TB disease and TB patient at pre-program and this percent was slightly increase (66.4\%) post program. Nevertheless, (31.5\%) of studied nurses were in high level of attitude toward herself if she became TB patient at pre-program and this percent was improved to $38.3 \%$ post program. There was no statistical significant difference. This was in accordance the study done in Zambia by (Mulenga, et.al. 2010) stated that most of the respondent have positive attitude and the majority also scored high in all subscales of attitudes ${ }^{(32)}$.

\section{Conclusion}

Better training of TB care providers and district supervisory support could be important interventions to improve the quality of care delivery and patient adherence to treatment.

\section{Recommendations}

The following recommendations emanate from our study:

1. Increasing the area of educational intervention about tuberculosis to include general hospitals and private clinics is essential.

2. Continuous training of the health care providers to upgrade their scientific knowledge is vital for educating patients.

3. The design of health educational programs to increase patients' general awareness about the disease is crucial to the control of the infection.

4. Improve the quality and number of television's educational programs to increase the population knowledge and to change their attitudes towards TB.

\section{References}

[1]. World Health Organization. Global tuberculosis control: WHO report 2010. WHO/ HTM/TB/2010.7. Genev World HealthOrganization. http://www.who.int/tb/publications/global_report/2010/en/index.html; 2010.

[2]. WHO. World Health Organization Global tuberculosis control surveillance planning financing. 2006:http://www.who.int/tb/publications/global-report/2004/en/index.html.

[3]. World Health Organization. The Stop TB Strategy: building on and enhancingDOTS to meet the TB-related millennium development goals. WHO/HTM/TB/2006.368. Geneva: World Health Organization. http://www.who.int/tb/strategy/en/index.html; 2006.

[4]. Laserson $\mathrm{K}$ and Wells $\mathrm{C}$. Reaching the targets for tuberculosis control: the impactof HIV. Bull World Health Organ, 2007;85(5):377-81.World Health Organization. Multidrug and extensively drug-resistant TB(M/XDRTB): 2010 global report on surveillance and response. WHO/HTM/TB/2010.3.Genev

[5]. World Health Organization. http://www.who.int/tb/features_archive/m_xdrtb_facts/en/index.html; 2010

[6]. Teixeira E, Menzies D, Cunha A,Luiz R, Ruffino-Netto A, Scartozzoni M, Portela P, and Trajman A. Knowledge and practices of medical students to prevent tuberculosis transmission in Rio de Janeiro, Brazil. Rev Panam Salud Publica/Pan Am J Public Health,2008; 24(4):265-70

[7]. Menzies D, Joshi R, Pai M. Risk of tuberculosis infection and disease associated with work in health care settings. Int J Tuberc Lung Dis, 2007; 11(6):593-605.

[8]. Abbas M, AlHamdan N, Fiala L, AlEnezy A and AlQahtani M. Prevalence of Latent TB among Health Care Workers in Four Major Tertiary Care Hospitals in Riyadh, Saudi Arabia.J Egypt Public Health Assoc ,2010; 85 ( 1 \& 2):60-71.

[9]. Philip C, Madhukar P. Tuberculosis, vulnerability, and access to quality care. JAMA, 2005;293(22):2790-3.

[10]. World Health Organization. An expanded DOTS framework for effective tuberculosis control. Geneva: WHO; 2002.

[11]. World Health Organization, Treatment of tuberculosis: guidelines for National Programmes. ${ }^{\text {rd }}$ ed. Geneva; 2003.

[12]. Ahmed A, Soliman S and Awad L. Validation of evidence-based clinical practice guideline: Nursing intervention for newly diagnosed pulmonary tuberculosis patients at community setting. Alexandria Journal of Medicine, 2012; 48:155-165.

[13]. MANUAL OF TUBERCULOSIS CONTROL IN EGYPT. 2006.

[14]. Cramm J and Nieboer A . The relationship between (stigmatizing) views and lay public preferences regarding tuberculosis treatment in the Eastern Cape, South Africa. International Journal for Equity in Health, 2011; 10:2.

[15]. HoaaN, Chuca $\mathrm{N}$ and Thorson A.Knowledge, attitudes, and practices about tuberculosis and choice of communication channels in a rural community in Vietnam.Health Policy, 2009; $90: 8-12$

[16]. Akin S, Gorak G, UnsarS, Mollaoglu M, Ozdilli K and DurnaZ. Knowledge of and attitudes toward tuberculosis of Turkish nursing and midwifery students Nurse Education Today .2011; xxx : xxx-xxx.

[17]. Lafaiete R, Motta M and Villa T . User Satisfaction in the Tuberculosis Control Program in a City in Rio de Janeiro, Brazil. Rev. Latino-Am. Enfermagem.2011;19(3):508-14.

[18]. Arakawa T, ArcênciR, ScatolinB, Scatena L, Ruffino-Netto R and Villa T. Accessibility to tuberculosis treatment: assessment of health service performance. Rev. Latino-Am. Enfermagem. 2011; 19(4):994-1002. 
Tuberculosis patients' perspective of quality of care provided by nurses after implementing ...

[19]. Mesfin M, Newell J, WalleyJ, GessessewA, TesfayeT, LemmaF and MadeleyR. Quality of tuberculosis care and its association with patient adherence to treatment in eight Ethiopian districts. Health Policy and Planning. 2009;24:457-66.

[20]. Tuberculosis Coalition for Technical Assistance.QUOTE-TB Measuring the quality of TB services: the patient's perspective.2007.

[21]. Yadav S, Mathur M and DixitA. Knowledge and attitude towards tuberculosis among sandstone quarry in desert parts of Rajasthan.Indian Journal of Tuberculosis.2006;53:187-95.

[22]. Abebe G, Deribew A, Apers L, Woldemichael K Shiffa J, Tesfaye M etal., Knowledge, Health Seeking Behavior and Perceived Stigma towards Tuberculosis among Tuberculosis Suspects in a Rural Community in Southwest Ethiopia.Plos One.2010;5(10).

[23]. Lange J. Testing Equivalence of Spanish and English Versions: The La Monica-Oberst (Revised) Patient Satisfaction With Nursing Care Scale. Research in Nursing \& Health, 2002; 25: 438-51.

[24]. World Health Organization. Global tuberculosis control: a short update to the 2009 report. Geneva: WHO; 2009.

[25]. World Health Organization, Global Tuberculosis Control. WHO Report 2002. WHO/CDS/TB/2002.295. Geneva, Switzerland: WHO 2002.

[26]. Lonnroth K, Raviglione M. Global epidemiology of tuberculosis: Prospects for control . Semin Respir Crit Care Med ,2008;29(5):481 - 91 .

[27]. WHO, 2008. Global tuberculosis control. WHO/HTM/B/2008.393.Geneva:World Health Organization

[28]. Lalloo U and Pillay S. Managing tuberculosis and HIV in subsahara Africa. Curr HIV/AIDS Rep, 2008;5(3):132-39.

[29]. World Health Organization: Global Tuberculosis Control: WHO Report 2000. WHO, Geneva:WHO/CDS/TB/2000.275.

[30]. Mweemba P, Haruzivishe C, Siziya S, Chipimo PJ, Cristenson K and Johansson E. Knowledge, attitude and compliance with Tuberculosis treatment, Lusaka, Zambia. Medical Journal of Zambia, 2008;35 (4): 121-128.

[31]. Boateng S A, Kodama T, Tachibana T and Hyoi N. Factors Contributing to Tuberculosis (TB) Defaulter Rate in New Juaben Municipality in the Eastern Region of Ghana. Journal of the National Institute of Public Health, 2010; 59 (3):291 - 97.

[32]. Mulenga C, Mwakazanga D, VereeckenK, et.al. Management of pulmonary tuberculosis patients in an urban setting in Zambia. BMC Public Health 2010, 10: 756. http://www.Biomedcenteral.com/1471-2458/10/756.

[33]. Ahmed J, Irfan M, Zaki A, et.al. Knowledge, attitude and misconceptions regarding tuberculosis in Pakistani patients. J Pak Med Assoc, 2006; 56(5): 211-214.

[34]. Mohamed A, Yousif M, Ottoa P and Bayoumi A. Knowledge of Tuberculosis: A Survey among Tuberculosis Patients in Omdurman, Sudan. Sudanese Journal of Public Health: January ,2007; 2 (1): 21.

[35]. Moharana P, Satapathy D, Sahani N, Behera T, Jena D, and Tripathy R. An analysis of treatment outcome among TB patient put under DOTS at a tertiary level health facility of Orissa. Journal of Community Medicine, July-Dec ,2009; 5 (2): 487-89.

[36]. Croft R and Croft R. knowledge, attitude and practice regarding leprosy and Tuberculosis in Bangladesh. Lepr Rev , 1999; 70:34-42.

[37]. Hoa N, Thorson A, Long N and Diwan V: Knowledge of Tuberculosis and associated health seeking behavior among rural Vietnamese adults with a cough for at least three weeks. Scand J Public Health suppl , 2003; 62:59-65.

[38]. Salomon L, Gasquet I, Mesbah M, and Ravaud P. Construction of a scale measuring inpatients' opinion on quality of care. International Journal for Quality In Health care,1999; 11(6): 507-16.

[39]. Billingsley K, Smith N, Shirley R, Achieng L and Keiser P. A quality assessment tool for tuberculosis control activities in resource limited setting. Tuberculosis, 2011;9: 549-53.

[40]. Babikak H, Neuhauser D Katamba A and Mupere E: Patient satisfaction, feasibility and reliability of satisfaction questionnaire among patients with pulmonary tuberculosis in urban Uganda: a cross-sectional study. Health Research Policy and Systems ,2011; 9:6 http://www.health-policy-systems.com/content/9/1/6

[41]. Hashim D, Al Kubaisy W and Al Dulayme A. Knowledge, attitude and practices survey among health care workers and tuberculosis patients In Iraq. Eastern Mediterranean health Journal, 2003; 9(4): 718- 31.

[42]. Naidoo S, Taylor M, Esterhuizen TM, Nordstrom DL, Mohamed O, Knight SE, Jinabhai CC. Changes in Healthcare Workers' Knowledge about Tuberculosis Following a Tuberculosis Training Programme. Education for Health, 24(2), 2011; 783-8. Available at: http://www.educationforhealth.net/

[43]. Johansson E, Diwan V, Huong N and Ahlberg B. Staff and patient attitudes to tuberculosis and compliance with treatment: an exploratory study in a district in Vietnam. Tubercle and Lung Disease, 1996; 77: 178-83.

[44]. Singla N, Sharma P and Jain R. Awareness about tuberculosis among nurses working in a tuberculosis hospital and in a general hospital in Delhi, India. INT J TUBERC LUNG DIS, 1998; 2(12):1005-10.

Table (1): Distribution of studied patients according to their demographic characteristics

\begin{tabular}{|c|c|c|}
\hline Variables & Patient $(n=37)$ & \\
\hline Age & No & $\%$ \\
\hline$<20$ & 2 & 5.4 \\
\hline $20-39$ & 11 & 29.7 \\
\hline 40 and more & 24 & 64.9 \\
\hline Range & \multirow{2}{*}{\multicolumn{2}{|c|}{$\begin{array}{c}15-82 \\
41.216 \pm 15.094\end{array}$}} \\
\hline Mean \pm SD & & \\
\hline Sex & & \\
\hline Male & 33 & 89.2 \\
\hline Female & 4 & 10.8 \\
\hline Marital status & & \\
\hline Single & 8 & 21.6 \\
\hline Married & 26 & 70.3 \\
\hline Divorced & 1 & 2.7 \\
\hline widow & 2 & 5.4 \\
\hline Family size & & \\
\hline $1-2$ & 6 & 16.2 \\
\hline $2-3$ & 12 & 32.4 \\
\hline $3-4$ & 9 & 24.3 \\
\hline More than 4 & 10 & 27.1 \\
\hline Residence & & \\
\hline Rural & 22 & 59.5 \\
\hline Urban & 15 & 40.5 \\
\hline
\end{tabular}


Tuberculosis patients' perspective of quality of care provided by nurses after implementing ...

\begin{tabular}{|l|c|c||}
\hline Education & 16 & \\
Illiterate & 8 & 43.2 \\
Read and write & 9 & 21.7 \\
Secondary & 4 & 24.3 \\
University & 23 & 10.8 \\
\hline Occupation & 14 & 62.2 \\
Working & 26 & 37.8 \\
Not working & 11 & 70.3 \\
\hline Smoking & 11 & 29.7 \\
Yes & 26 & 29.7 \\
\hline No & & 70.3 \\
\hline Are there difficulties to reach to hospital? & & \\
Yes & & \\
No & & \\
\hline
\end{tabular}

Table (2): Patients' general knowledge about TB and its treatment

\begin{tabular}{||l|c|c|c||}
\hline \multicolumn{1}{|c|}{ Patient knowledge } & Max score & Mean percent & Mean \pm SD \\
\hline \hline General aspects of tuberculosis. & $\mathbf{1 1}$ & $62.7 \%$ & $6.8919 \pm 2.7967$ \\
\hline Factors contribute to TB. & $\mathbf{8}$ & $34.8 \%$ & $2.7838 \pm 1.9598$ \\
\hline Sign and symptoms. & $\mathbf{1 0}$ & $61.4 \%$ & $6.1351 \pm 3.7429$ \\
\hline Complication of irregular treatment. & $\mathbf{4}$ & $29.7 \%$ & $1.1892 \pm 0.9672$ \\
\hline Prevention measures. & $\mathbf{6}$ & $50.5 \%$ & $3.0270 \pm 1.9363$ \\
\hline $\begin{array}{l}\text { Searching of the patient for concealing before they were } \\
\text { reached to the TB hospital. }\end{array}$ & $\mathbf{1}$ & $89.2 \%$ & $0.8918 \pm 0.3148$ \\
\hline Types of investigation. & $\mathbf{4}$ & $60.1 \%$ & $2.4054 \pm 0.9563$ \\
\hline Time of take medication. & $\mathbf{4}$ & $22.3 \%$ & $0.8918 \pm 0.3148$ \\
\hline Curability of the disease. & $\mathbf{3}$ & $13.5 \%$ & $0.4054 \pm 0.4977$ \\
\hline Protection of the family from TB infection & $\mathbf{4}$ & $46.6 \%$ & $1.8649 \pm 1.3573$ \\
\hline \multicolumn{1}{|c|}{ Total Mean \pm SD } & $\mathbf{5 5}$ & $48.2 \%$ & $26.4865 \pm 10.8976$ \\
\hline \multicolumn{2}{|l}{} \\
\hline
\end{tabular}

Figure (1): Correlation of patient knowledge regarding TB and their level of education $(n=37)$

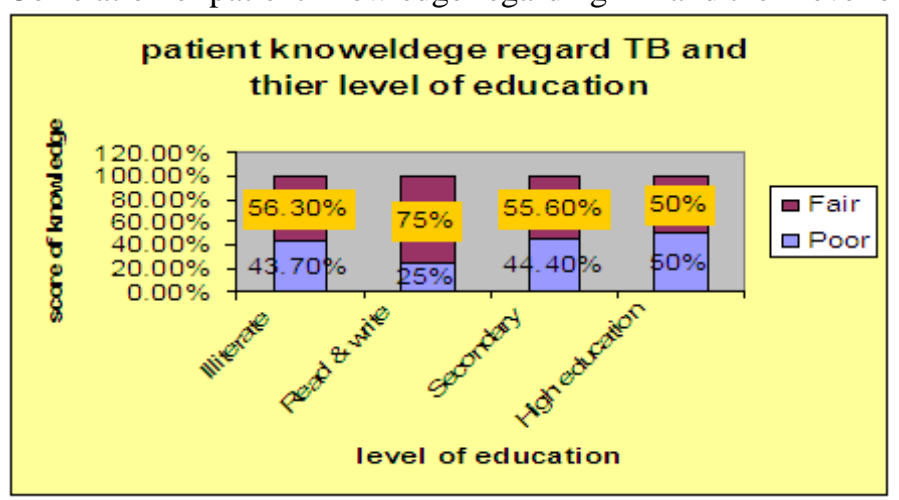

Table(3):Quality of nursing care provided to TB patient regarding to importance of TB quality aspects and performance of facility according to patient response

\begin{tabular}{|c|c|c|c|c|c|c|c|c|c|c|c|c|c|c|}
\hline \multirow{3}{*}{$\begin{array}{l}\text { Patient attitude } \\
\text { dimensions }\end{array}$} & \multicolumn{6}{|c|}{ Importance of quality aspects } & \multicolumn{8}{|c|}{ Performance of facility } \\
\hline & \multicolumn{2}{|c|}{ Very important } & \multicolumn{2}{|c|}{ Important } & \multicolumn{2}{|c|}{ Not important } & \multicolumn{2}{|c|}{ Usually } & \multicolumn{2}{|r|}{ Often } & \multicolumn{2}{|c|}{ Sometimes } & \multicolumn{2}{|c|}{ Never } \\
\hline & No & $\%$ & NO & $\%$ & No & $\%$ & No & $\%$ & No & $\%$ & No & $\%$ & NO & $\%$ \\
\hline Availability of services & 32 & $86.5 \%$ & 5 & $8.1 \%$ & 0 & $0.00 \%$ & 19 & $51.4 \%$ & 7 & $18.9 \%$ & 6 & $16.2 \%$ & $\overline{5}$ & $13.5 \%$ \\
\hline $\begin{array}{l}\text { Information about TB and } \\
\text { its treatment. }\end{array}$ & 36 & $97.3 \%$ & 1 & $2.7 \%$ & 0 & $0.00 \%$ & 14 & $37.8 \%$ & 5 & $13.5 \%$ & 5 & $13.5 \%$ & 13 & $35.1 \%$ \\
\hline 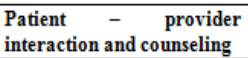 & 35 & $94.6 \%$ & 2 & $5.4 \%$ & 0 & $0.00 \%$ & 18 & $48.6 \%$ & 10 & $27 \%$ & 5 & $13.5 \%$ & 4 & $10.8 \%$ \\
\hline $\begin{array}{l}\text { Infrastructure of the TB } \\
\text { facility you are visiting. }\end{array}$ & 37 & $100 \%$ & 0 & $0.00 \%$ & 0 & $0.00 \%$ & 11 & $29.7 \%$ & 9 & $24.3 \%$ & 10 & $27 \%$ & 7 & $18.9 \%$ \\
\hline TB procedures and tests. & 36 & $97.3 \%$ & 1 & $2.7 \%$ & 0 & $0.00 \%$ & 2 & $5.4 \%$ & 1 & $2.7 \%$ & 33 & $89.2 \%$ & 1 & $2.7 \%$ \\
\hline Costs and payment & 37 & $100 \%$ & 0 & $0.00 \%$ & 0 & $0.00 \%$ & 37 & $100 \%$ & 0 & $0.00 \%$ & 0 & $0.00 \%$ & 0 & $0.00 \%$ \\
\hline $\begin{array}{l}\text { Support received from the } \\
\text { TB facility you are visiting. }\end{array}$ & 36 & $97.3 \%$ & 1 & $2.7 \%$ & 0 & $0.00 \%$ & 0 & $0.00 \%$ & 0 & $0.00 \%$ & 0 & $0.00 \%$ & 37 & $100 \%$ \\
\hline
\end{tabular}


Tuberculosis patients' perspective of quality of care provided by nurses after implementing ...

Table (4): Distribution of nurses according to their demographic characteristics

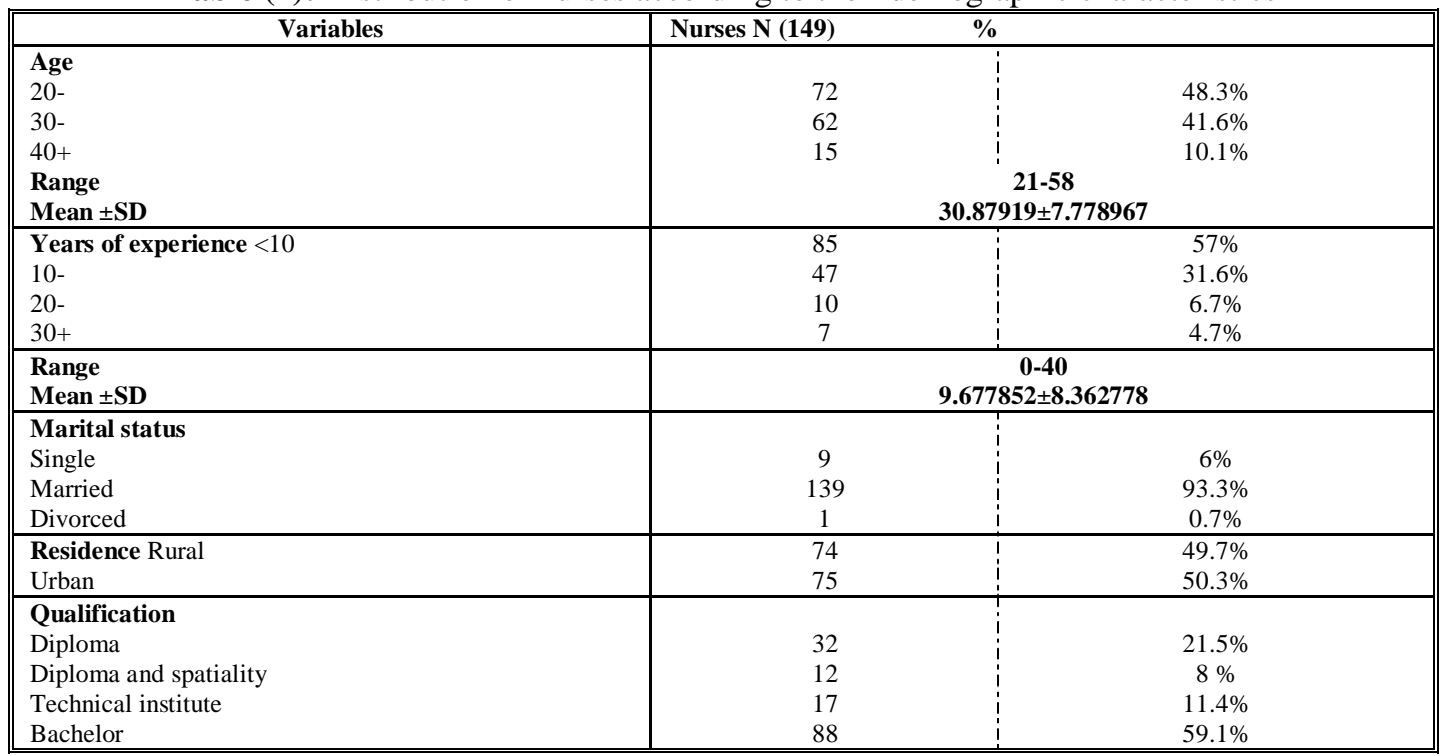

Table (5): Distribution of nurses according to their mean score of knowledge regarding TB in the El-Gharbia Governorate in pre and post the educational program.

\begin{tabular}{|c|c|c|c|c|c|c|}
\hline \multirow[b]{2}{*}{ Dimensions of nurses` TB knowledge } & \multirow[b]{2}{*}{$\begin{array}{l}\text { Total } \\
\text { score }\end{array}$} & \multicolumn{2}{|c|}{ Pre $(n=149)$} & \multicolumn{2}{|c|}{ Post $(n=149)$} & \multirow{2}{*}{$\begin{array}{c}\text { Paired t test } \\
\text { p- value }\end{array}$} \\
\hline & & Mean \pm SD & $\begin{array}{c}\text { Mean } \\
\text { percent }\end{array}$ & Mean \pm SD & $\begin{array}{c}\text { Mean } \\
\text { percent }\end{array}$ & \\
\hline $\begin{array}{l}\text { The definition, causes and } \operatorname{mood} \text { of } \\
\text { transmission of TB }\end{array}$ & 18 & $11.671 \pm 2.911$ & $76.5 \%$ & $20.95 \pm 2.06$ & $93.8 \%$ & $\begin{array}{c}-13.632 \\
0.000^{*}\end{array}$ \\
\hline Signs, symptoms and diagnosis of TB & 25 & $19.221 \pm 3.7123$ & $76.9 \%$ & $22.496 \pm 2.3954$ & $90 \%$ & $\begin{array}{l}-20.04 \\
0.000^{*}\end{array}$ \\
\hline Preventive measures and treatment of TB & 33 & $20.778 \pm 3.8341$ & $62.9 \%$ & $28.402 \pm 2.8018$ & $86.1 \%$ & $\begin{array}{l}-19.525 \\
0.000^{*}\end{array}$ \\
\hline Total score of knowledge & 76 & $54.872 \pm 7.0923$ & $72.2 \%$ & $67.785 \pm 5.1642$ & $89.2 \%$ & $\begin{array}{c}-17.978 \\
0.000^{*} \\
\end{array}$ \\
\hline
\end{tabular}

* Significant at $\mathrm{P} \leq 0.05$

Table (6): Distribution of nurses' level of knowledge about tuberculosis in the El-Gharbia Governorate pre and post the program

\begin{tabular}{|c|c|c|c|c|c|c|c|}
\hline \multirow{3}{*}{$\begin{array}{l}\text { Dimensions of nurses` } \mathrm{TB} \\
\text { knowledge }\end{array}$} & \multicolumn{6}{|c|}{ Level of nurses knowledge $(n=149)$} & \multirow{3}{*}{$\begin{array}{c}X^{2} \\
\text { P- value }\end{array}$} \\
\hline & \multicolumn{3}{|c|}{ Pre } & \multicolumn{3}{|c|}{ Post } & \\
\hline & $\begin{array}{l}\text { Poor } \\
\mathrm{N} \%\end{array}$ & $\begin{array}{l}\text { Fair } \\
\mathrm{N} \%\end{array}$ & $\begin{array}{l}\text { Good } \\
\mathrm{N} \%\end{array}$ & $\begin{array}{l}\text { Poor } \\
\mathrm{N} \%\end{array}$ & $\begin{array}{l}\text { Fair } \\
\mathrm{N} \%\end{array}$ & $\begin{array}{l}\text { Good } \\
\mathrm{N} \%\end{array}$ & \\
\hline $\begin{array}{l}\text { The definition, causes and mood of } \\
\text { transmission of TB }\end{array}$ & $\begin{array}{l}20 \\
13.4 \% \\
\end{array}$ & $\begin{array}{l}52 \\
34.9 \% \\
\end{array}$ & $\begin{array}{l}77 \\
51.7 \% \\
\end{array}$ & $\begin{array}{ll}0 \\
0.00 \% \\
\end{array}$ & $\begin{array}{l}10 \\
6.7 \% \\
\end{array}$ & $\begin{array}{l}139 \\
92.3 \% \\
\end{array}$ & $0.000^{*}$ \\
\hline Signs, symptoms and diagnosis of TB & $\begin{array}{l}27 \\
18.1 \% \\
\end{array}$ & $\begin{array}{l}46 \\
30.9 \% \\
\end{array}$ & $\begin{array}{l}76 \\
51 \% \\
\end{array}$ & $\begin{array}{l}2 \\
1.3 \% \\
\end{array}$ & $\begin{array}{l}12 \\
8.1 \% \\
\end{array}$ & $\begin{array}{l}135 \\
90.6 \%\end{array}$ & $0.000 *$ \\
\hline $\begin{array}{l}\text { Preventive measures and treatment } \\
\text { of TB }\end{array}$ & $\begin{array}{l}11 \\
7.4 \% \\
\end{array}$ & $\begin{array}{l}52 \\
34.9 \% \\
\end{array}$ & $\begin{array}{l}86 \\
57.7 \% \\
\end{array}$ & 1 & $\begin{array}{l}21 \\
14.1 \% \\
\end{array}$ & $\begin{array}{l}127 \\
85.2 \%\end{array}$ & $0.000^{*}$ \\
\hline Total level of knowledge & $\begin{array}{l}18 \\
12.1 \%\end{array}$ & $\begin{array}{l}56 \\
37.6 \% \\
\end{array}$ & $\begin{array}{l}75 \\
50.3 \%\end{array}$ & 1 & $\begin{array}{l}4 \\
2.7 \% \\
\end{array}$ & $\begin{array}{l}144 \\
96.6 \%\end{array}$ & $0.000^{*}$ \\
\hline
\end{tabular}

* Significant at $\mathrm{P} \leq 0.05$

Table (7): Attitude of nurses regarding TB disease, TB patients and attitude toward herself if she become TB patient in the Al-Gharbia Governorate pre and post the nursing intervention program

\begin{tabular}{|c|c|c|c|c|c|c|c|}
\hline \multirow{3}{*}{ Dimensions } & \multicolumn{3}{|c|}{ Pre $(n=149)$} & \multicolumn{3}{|c|}{ Post $(n=149)$} & \multirow{3}{*}{$\begin{array}{c}X^{2} \\
P \text {-value }\end{array}$} \\
\hline & low & Moderate & High & low & Moderate & High & \\
\hline & $\begin{array}{l}\mathrm{N} . \\
\%\end{array}$ & $\begin{array}{l}\mathrm{N} . \\
\%\end{array}$ & $\begin{array}{l}\mathbf{N} . \\
\%\end{array}$ & $\begin{array}{l}\mathbf{N} . \\
\%\end{array}$ & $\begin{array}{l}\mathbf{N} . \\
\%\end{array}$ & $\begin{array}{l}\mathrm{N} . \\
\%\end{array}$ & \\
\hline $\begin{array}{l}\text { 1. Attitude regarding TB disease } \\
\text { and TB patients }\end{array}$ & $\begin{array}{c}39 \\
26.2 \%\end{array}$ & $\begin{array}{c}15 \\
10.1 \%\end{array}$ & $\begin{array}{c}95 \\
63.7 \%\end{array}$ & $\begin{array}{c}38 \\
25.5 \%\end{array}$ & $\begin{array}{c}12 \\
8.1 \%\end{array}$ & $\begin{array}{c}99 \\
66.4 \%\end{array}$ & 0.8070 \\
\hline $\begin{array}{l}\text { 2. Attitude toward herself if she } \\
\text { become TB patient }\end{array}$ & $\begin{array}{c}79 \\
53 \%\end{array}$ & $\begin{array}{c}23 \\
15.5 \%\end{array}$ & $\begin{array}{c}47 \\
31.5 \%\end{array}$ & $\begin{array}{c}74 \\
49.6 \%\end{array}$ & $\begin{array}{c}18 \\
12.1 \%\end{array}$ & $\begin{array}{c}57 \\
38.3 \% \\
\end{array}$ & 0.4200 \\
\hline Total & $\begin{array}{c}56 \\
37.6 \%\end{array}$ & $\begin{array}{c}18 \\
12.1 \%\end{array}$ & $\begin{array}{c}75 \\
50.3 \%\end{array}$ & $\begin{array}{c}54 \\
36.2 \%\end{array}$ & $\begin{array}{c}13 \\
8.7 \%\end{array}$ & $\begin{array}{c}82 \\
55 \%\end{array}$ & 0.5613 \\
\hline
\end{tabular}

